\title{
Improvement of corrosion resistance and bio compatibility of medical Nickel-Titanium alloys through forming $\mathrm{TiO}_{2}$ thin film
}

\author{
Y. Kimura \\ Dept. of Materials Science and Technology, Kogakuin University, Japan
}

\begin{abstract}
Nickel-Titanium alloys have been investigated for applying to various surgical procedures. However, little is known about the toxicity of Ni-elements and the actual conditions of surface modification of Ni-Ti alloy for preventing the toxicity of $\mathrm{Ni}$. In this study, the corrosion resistance of Ni-Ti alloys was improved through making $\mathrm{TiO}_{2}$ thin film by conducting in air oxidation and reactive sputtering. These thin films were characterized using FE-SEM, XRD, XPS and AFM. And judging from the polarization curves obtained by electrochemical measurement in a quasi-living body environment, corrosion resistance of $\mathrm{Ni}$-Ti super elastic alloy was evaluated. In addition, the effect of air oxidized $\mathrm{Ni}-\mathrm{Ti}$ alloy specimen upon cell multiplication and morphological change of cell were investigated by culturing cell $72 \mathrm{hrs}$ on $\mathrm{Ni}-\mathrm{Ti}$ alloy specimen surface with $\mathrm{TiO}_{2}$ thin film. From these considerations, some trials for establishing a method for $\mathrm{TiO}_{2}$ thin film formation on the surface of Ni-Ti alloy were conducted from the view point of improving biocompatibility.

Keywords: Nickel-Titanium alloy, corrosion resistance, bio compatibility, surface modification, $\mathrm{TiO}_{2}$ thin film, air oxidation, reactive sputtering, cell multiplication and morphological change of cell, air oxidation under suppressed partial pressure oxygen condition.
\end{abstract}

\section{Introduction}

In recent years, some concerns have been raised about the corrosion resistance for implant alloys with aging society. Implant materials have demanded biocompatibility for a long term without a re-operation. The biocompatibility of implant materials means not giving bad influence to living body and not losing 
functions of materials interested. Especially, the strength degradation by corrosion and elution of a toxic metallic ion by corrosion has attracted a growing interest in the severe living body environment. Shape memory effect and super elasticity effect of $\mathrm{Ni}-\mathrm{Ti}$ alloys $[1,2]$ have received considerable attention in a medical domain [3-6]. And the application of Ni-Ti alloys in medical devices has been the subject of many research papers. However in practical case, Ni element ( $\mathrm{Ni}$ ion) in $\mathrm{Ni}-\mathrm{Ti}$ alloys has been apprehensive for application due to carcinogenicity and allergic reaction [7]. In the present state of affairs, the use of $\mathrm{Ni}-\mathrm{Ti}$ alloys is negative in the medical domain. A comprehensive understanding of the surface modification of Ni-Ti alloys for using under quasi-living body environment is still lacking.

Therefore in this paper, the corrosion resistance of $\mathrm{Ni}$-Ti alloys was improved through making $\mathrm{TiO}_{2}$ thin film. $\mathrm{TiO}_{2}$ thin film has been studied for the photocatalyst, and a lot of production methods have been developed. In this study, $\mathrm{TiO}_{2}$ thin film was made by air oxidation and reactive sputtering. Air oxidation is a comparatively simple thin film making method and thin films made by this method do not easily exfoliate. Reactive sputtering is the film making method that can control forming condition precisely and thin films made by this method are high coherent. These thin films were characterized using FESEM, XRD, XPS and AFM. And judging from the polarization curves obtained by electro-chemical measurement in quasi-living body environment, corrosion resistance of Ni-Ti super elastic alloy was evaluated. In addition, effect of air oxidized Ni-Ti alloy specimen upon cell multiplication and morphological change of cell were investigated by culturing cell $72 \mathrm{hrs}$ on Ni-Ti alloy specimen surface with $\mathrm{TiO}_{2}$ thin film.

From these considerations, some trials for establishing a method for $\mathrm{TiO}_{2}$ thin film formation on the surface of $\mathrm{Ni}-\mathrm{Ti}$ alloy were conducted from the view point of improving biocompatibility.

\section{Experimental procedures}

\subsection{Test specimen}

Plate specimens whose size of $11.5 \times 11.5 \times 2.5 \sim 3.0 \mathrm{~mm}$ were cut from the block of Ni-Ti alloy ( $44 \%$ titanium, $56 \%$ nickel by weight). Samples were finished by mechanical abrasion, and samples polished to a mirror finish. The test specimen was ultrasonic cleaned in ethanol. Air oxidation treatments were performed in an electric furnace in oxidizing atmosphere. Four kinds of samples (A1-A4) were prepared through changing the heat treatment temperature and heating time (A1;673K-30min, A2;773K-30min, A3;773K-60min, A4;1073K-30min) [8].

DC reactive sputtering system (MPS-2000-HC3, ALVAC) was employed for making $\mathrm{TiO}_{2}$ thin film [9]. The target is titanium with purity of $99.99 \%$. The distance between target and substrates was fixed at $200 \mathrm{~mm}$. After the chamber was evacuated to a vacuum lower than $\times 10^{-6} \mathrm{~Pa}$, argon was introduced into the chamber. Input power was fixed at $200 \mathrm{~W}$, and substrate temperature was not controlled. After the discharge color was confirmed, oxygen was introduced into 
the chamber. Three kinds of samples were prepared through change the ratio of argon and oxygen flow rate $\left(\mathrm{S} 1 ; \mathrm{Ar} \mathrm{O}_{2}=5: 10\right.$ [sccm], S2; $\mathrm{Ar}: \mathrm{O}_{2}=20: 10[\mathrm{sccm}]$, $\left.\mathrm{S} 3 ; \mathrm{Ar}_{2} \mathrm{O}_{2}=50: 10[\mathrm{sccm}]\right)$.

\subsection{Anodic polarization measurement}

The corrosion resistance was evaluated employing anodic polarization measurement method based on JIS T 0302 (Testing method for corrosion resistance of metallic biomaterials by anodic polarization measurement). Electrochemical measurement was conducted using three electrode method (HZ-3000 Hokutodenkou Japan) composed of specimen (working electrode), Pt (counter electrode) and the saturated calomel electrode (S.C.E.) (reference electrode). Electro-chemical measurement was conducted using plate specimen in lactated Ringer's solution at $310 \mathrm{~K}$. Test solution was deaerated by extra-high purity nitrogen for 20 minutes before testing to suppress dissolved oxygen level similar to the living body. Potentio-dynamic corrosion test was conducted with the sweep rate of $20 \mathrm{mV} / \mathrm{min}$ from $-1000 \mathrm{mV}$ to $2000 \mathrm{mV}$ (vs. S.C.E.)

\subsection{Evaluation of bio-compatibility of air oxidized Ni-Ti alloy}

As a final goal of biocompatibility evaluation inflammatory response of macrophage is planned to employ. In previous research, U937 (Human Leukemic Monocyte Lymphoma Cell) was used to differentiate into macrophage $[10,11]$. In this study, however, an osteoblast-like cell line MC3T3-E1 was applied because of improvement in reproducibility of test results due to its having no ability to differentiate into other cell systems.

At first, pure Ni square plate specimen $(27 \mathrm{~mm})$ whose thickness is $1.0 \mathrm{~mm}$ was dissolved in 1.0M phosphate buffer whose temperature is $310 \mathrm{~K}$ employing three electrode anodic polarization measurement method under constant current density condition of $130 \mathrm{~mA} / \mathrm{cm}^{2}$. Then through analyzing it by ICP, test solutions with various $\mathrm{Ni}$ ion concentration from 0.125 to $2.0 \mathrm{ppm}$ were prepared.

The effect of $\mathrm{Ni}$ ion concentration and upon cell multiplication and morphological change of cell was investigated. Also, effect of air oxidized Ni-Ti alloy specimen upon cell multiplication and morphological change of cell were investigated by culturing cell $72 \mathrm{hrs}$ on Ni-Ti alloy specimen surface with $\mathrm{TiO}_{2}$ thin film.

\section{Experimental results and discussions}

\subsection{Characterization of modified surface}

In Figure 1 FE-SEM morphology of Ni-Ti specimen surface, film thickness determined by FIB processing and SIM (Scanning Ion Microscope) observation and structure of thin film determined by XRD were summarized.

Then, the structural analysis of the thin film layer was conducted by sputtering and XPS [12]. From results of compositional analysis toward depth 


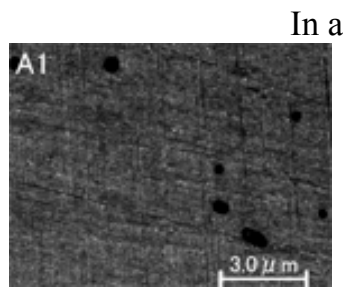

A1 (673K-30min) $\mathrm{t}=5 \sim 15 \mathrm{~nm}$

Anatase

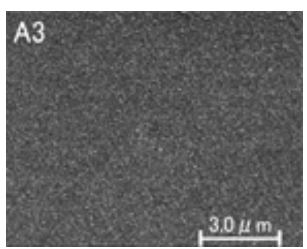

A3 (773K-60min) $\mathrm{t}=120 \sim 130 \mathrm{~nm}$

Rutile

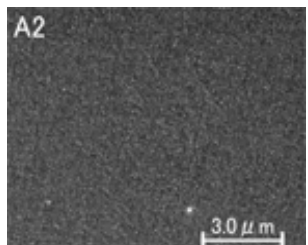

A2 (773K-30min) $\mathrm{t}=80 \sim 90 \mathrm{~nm}$

Anatase and Rutile

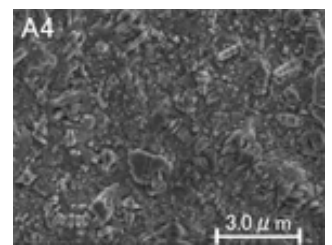

A4 (1073K-30min) $\mathrm{t}=2000 \mathrm{~nm}$

Rutile

$\mathrm{Ni}-\mathrm{Ti}$

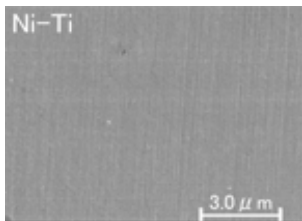

Reactive sputtering

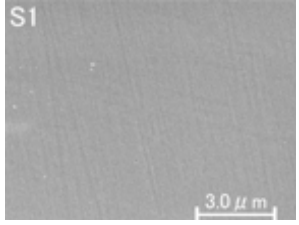

$\mathrm{S} 1$ (Ar:5sccm) $\mathrm{t}=60 \sim 70 \mathrm{~nm}$

Anataze

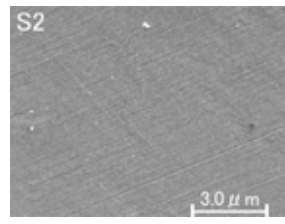

S2 (Ar:20sccm) $\mathrm{t}=70 \sim 80 \mathrm{~nm}$

Anataze

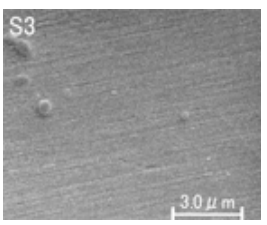

S3 (Ar:50sccm) $\mathrm{t}=95 \sim 105 \mathrm{~nm}$

Anataze

Figure 1: Morphology, film thickness and structure of surface modified specimens.

direction by XPS shown in Figure 2 the composition of extreme thin surface of specimen was understood. Thin $\mathrm{TiO}_{2}$ layer exists in the vicinity of film surface. In the thin film surface made by air oxidation a peak of $\mathrm{Ni}$ was observed, and it is considered that a Ni-free layer was not present on the surface of specimen. On the other hand, a peak of $\mathrm{Ni}$ was not observed on the surface of film made by 

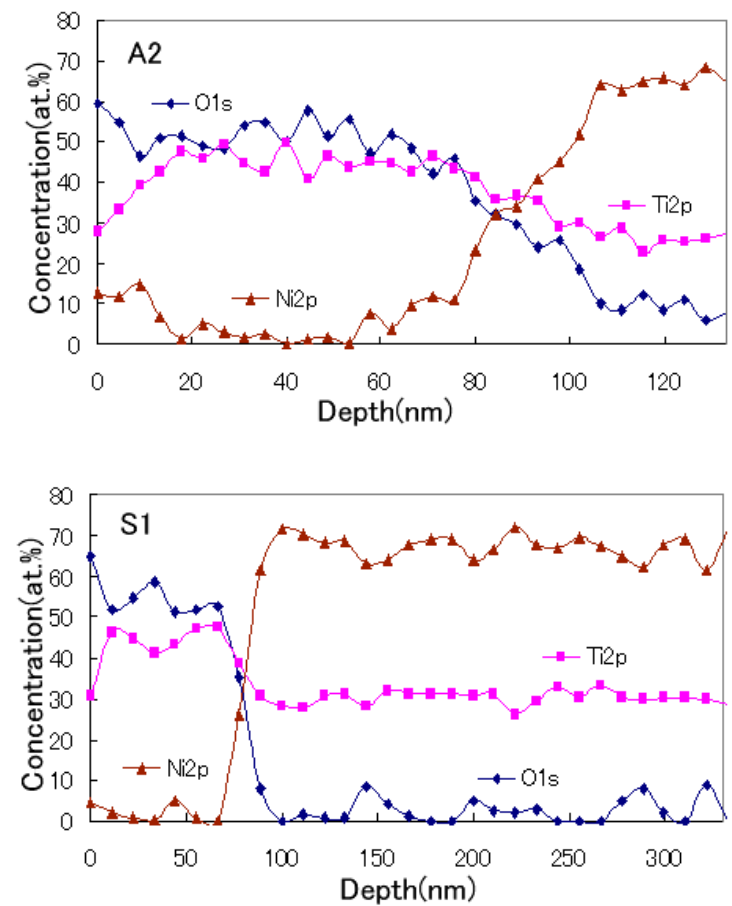

Figure 2: $\quad$ Analysis of composition toward depth direction by XPS.

reactive sputtering, it is considered that $\mathrm{Ni}$-free layer was provided on the surface of sputtered specimen.

\subsection{Evaluation of corrosion resistance by electro-chemical measurement}

Figures 3 and 4 show polarization curves obtained in lactaed Ringer's solution at $310 \mathrm{~K}$ by using in air oxidized and reactive sputtered $\mathrm{Ni}$-Ti alloy. From polarization curves obtained from in air oxidized specimen it can be understood that passivation current density were extremely suppressed compared with nontreated materials, and improvement of corrosion resistance was confirmed. As in air oxidation heat treatment temperature increases, film thicknesses increase and corrosion resistance improved from the view point of passivation current density. It is considered that corrosion resistance rather depends on films thickness than crystal structure. However, potential width of passive state remains approximately equal to virgin materials. From polarization curves of reactive sputtered specimen it can be stated that passivation current density were extremely improved compared with non-treated, and improvement of corrosion resistance were confirmed.

As Ar flow rate increases, film thicknesses increases and corrosion resistance improved. Potential width of passive state is wider than virgin material, bio compatibility without re-operation for a long term was expected. 


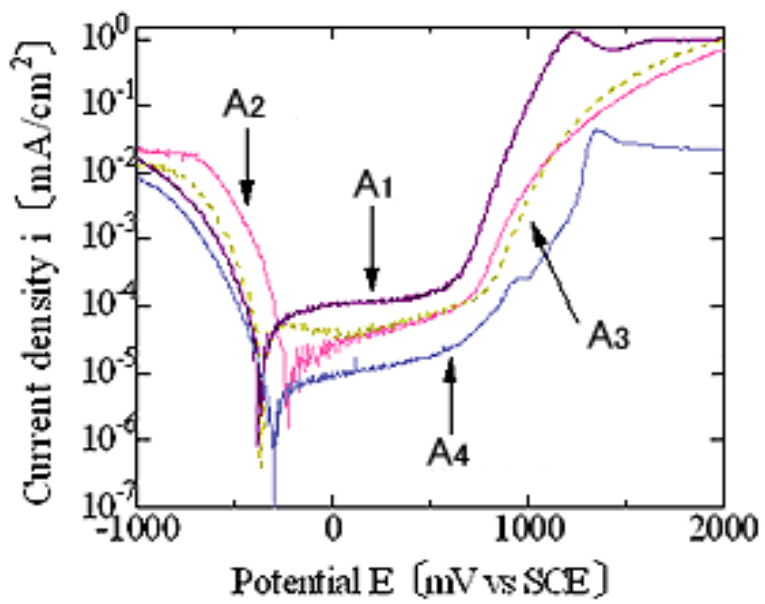

Figure 3: Polarization curves of surface modified of $\mathrm{Ni}$-Ti alloy (in air oxidation) in Lactic Ringer's solution of $310 \mathrm{~K}$.

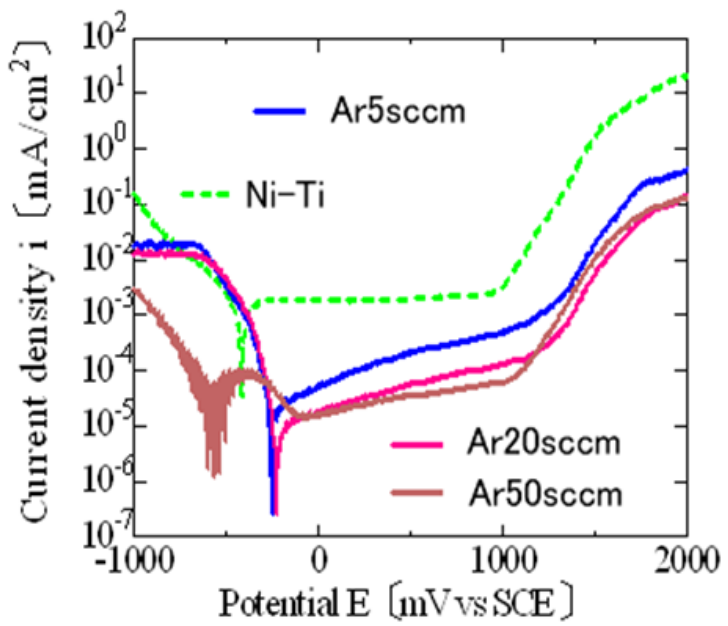

Figure 4: Polarization curves of reactive sputtered modified Ni-Ti alloy in Lactic Ringer's solution of $310 \mathrm{~K}$.

\subsection{Bio-compatibility of air oxidized Ni-Ti alloy specimen}

At first, effect of $\mathrm{Ni}$ ion concentration upon cell multiplication was investigated in this section. In Figure 5, number of adhered cells after cultured 72 hrs in $1.0 \mathrm{M}$ phosphate buffer with various $\mathrm{Ni}$ ion concentrations under 2 ppm or cultured 72 hrs on Ni-Ti alloy specimen surface with $\mathrm{TiO}_{2}$ thin film. Solid line shown in this figure indicates sowed cell density, that is, $5600 \mathrm{cells} / \mathrm{cm}^{2}$. From these result, cell multiplication was occurred under each ion concentration condition in the same 
manner as control. Therefore, no significant difference in the number of adhered cells was recognized. As a result, there is no effect of $\mathrm{Ni}$ ion upon cell multiplication within ion concentration blow $2 \mathrm{ppm}$. Also, in case of Ni-Ti alloy with $\mathrm{TiO}_{2}$ thin film formed by air oxidization, no effect of $\mathrm{Ni}$ ion dissolution from extreme thin surface layer upon cell multiplication was detected.

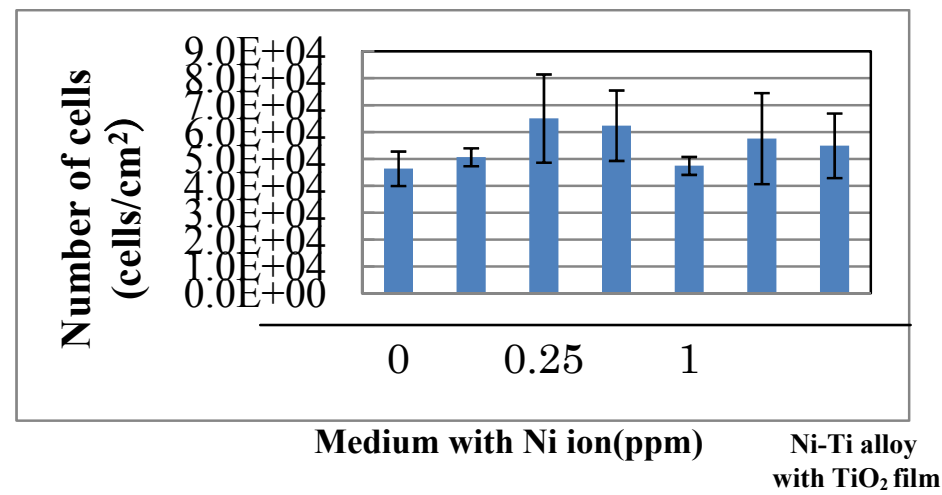

Figure 5: $\quad$ Number of adhered cells after cultured $72 \mathrm{hrs}$ in $1.0 \mathrm{M}$ phosphate buffer.

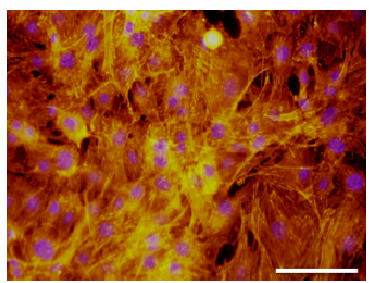

(a) fluorescent stain

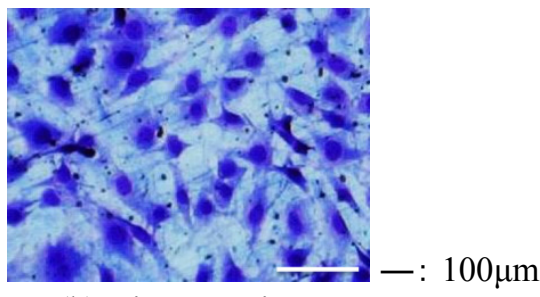

(b) Giemsa stain

Figure 6: Morphology of cell after cultured $72 \mathrm{hrs}$ on $\mathrm{Ni}-\mathrm{Ti}$ alloy specimen surface.

Then, effect of $\mathrm{Ni}$ ion concentration upon morphology change of cell was investigated. In Figure 6, morphology of cell after cultured $72 \mathrm{hrs}$ on Ni-Ti alloy specimen surface with $\mathrm{TiO}_{2}$ thin film were indicated. Figure 6(a) shows morphology of cell obtained after fluorescent stain, and (b) shows morphology of cell obtained after Giemsa stain. At the same time, in Figure 7(b), fluorescent stain morphology of cell after cultured $72 \mathrm{hrs}$ in $1.0 \mathrm{M}$ phosphate buffer with $0.5 \mathrm{ppm} \mathrm{Ni}$ ion concentration was indicated and in Figure 7(a) that of control was indicated. In case of cell after cultured $72 \mathrm{hrs}$ in $1.0 \mathrm{M}$ phosphate buffer with $\mathrm{Ni}$ ion concentration of $0.5 \mathrm{ppm}$, some morphological change, that is, linearization of cell was recognized. On the contrary, in case of cell after cultured $72 \mathrm{hrs}$ on $\mathrm{Ni}-\mathrm{Ti}$ alloy specimen surface with $\mathrm{TiO}_{2}$ thin film, no remarkable change in the morphology of cell was generated just like the case of control. 


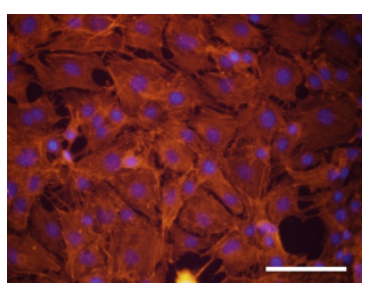

(a) Ni ion: 0 ppm

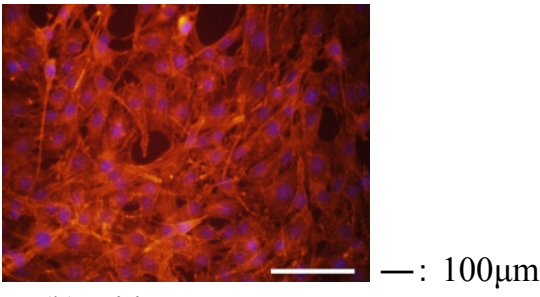

(b) Ni ion: $0.5 \mathrm{ppm}$

Figure 7: $\quad$ Morphology of cell after cultured $72 \mathrm{hrs}$ in $1.0 \mathrm{M}$ phosphate buffer with $0.5 \mathrm{ppm} \mathrm{Ni}$ ion.

From these observed results, $\mathrm{TiO}_{2}$ thin film formed by air oxidization also extremely contributes to improve bio compatibility of Ti-Ni alloy.

\subsection{Improvement of biocompatibility trough making optimal $\mathrm{TiO}_{2}$ thin film}

In this section, other trials of surface modifications were conducted. One is in air oxidation under suppressed partial pressure oxygen condition and another is sequential combination of electro- polishing and air oxidation. Figures 8 and 9 show polarization curves obtained in lactaed Ringer's solution at $310 \mathrm{~K}$ by using these two kinds of surface modified Ni-Ti alloy. From these figures, remarkable improvement in corrosion resistance was recognized both in above mentioned surface modified specimens compared with simply air oxidized specimen. This remarkable improvement in corrosion resistance may be brought about through eliminating Ni element in the extreme surface layer. Therefore, XPS analysis in extreme surface layer have to be conducted in near future. At the same time, improvement in biocompatibility may also be accomplished.

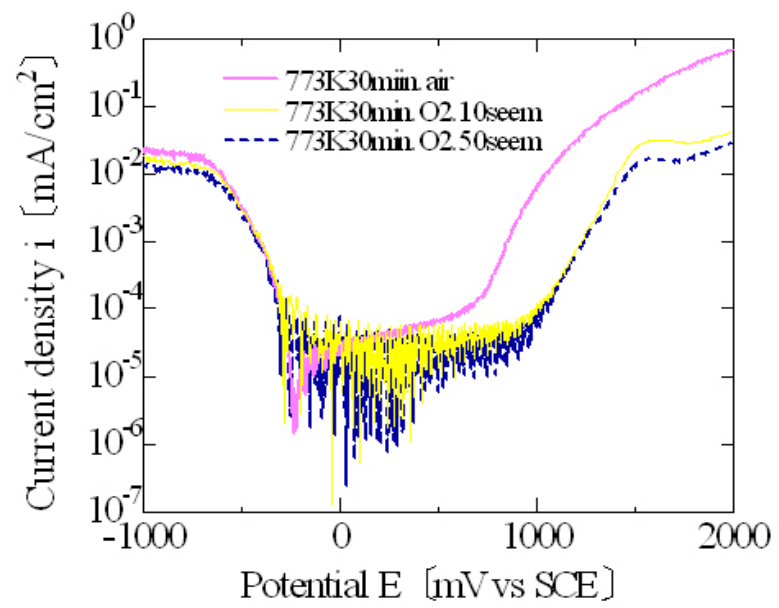

Figure 8: $\quad$ Polarization curves of Ni-Ti alloy oxidized in suppressed partial pressure air obtained in Lactic Ringer's Solution of 310K. 


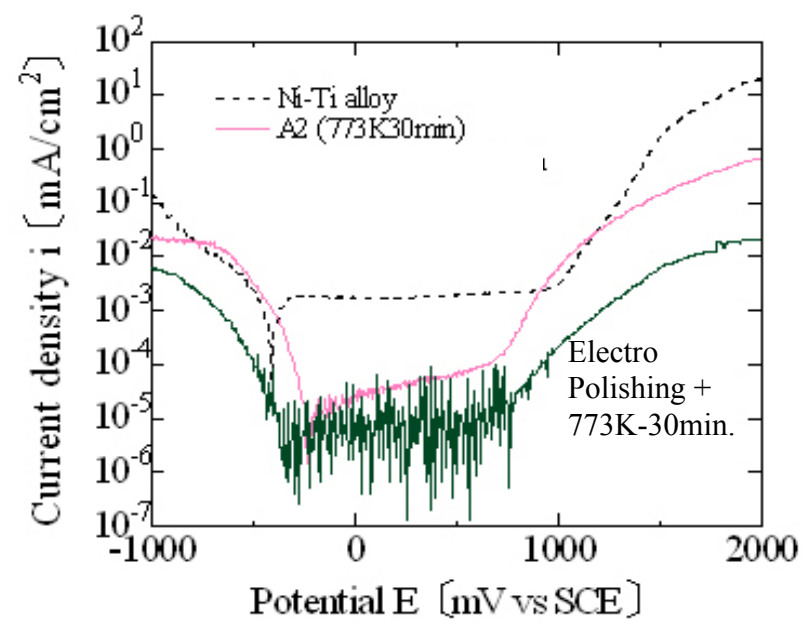

Figure 9: Polarization curves of complexly surface modified Ni-Ti alloy obtained in Lactic Ringer's Solution of 310K.

\section{Conclusions}

The corrosion resistance of Ni-Ti alloys was improved through making $\mathrm{TiO}_{2}$ thin film by air oxidation and reactive sputtering. Surface morphology, crystal structure and composition of films were characterized by FE-SEM, XRD and XPS. Then, the electro-chemical measurement in quasi-living body environment were conducted. In addition, bio compatibility of air oxidized Ni-Ti alloy was evaluated by cell multiplication and morphological change of cell.

Results obtained are summarized as follows;

1. A specimen with $\mathrm{TiO}_{2}$ film whose thickness is more than $100 \mathrm{~nm}$ showed sufficient corrosion resistance in quasi-human body environment. And corrosion resistance in quasi-human body environment was influenced more by a film thickness and film defects than crystal structures of $\mathrm{TiO}_{2}$.

2. In case of cell after cultured $72 \mathrm{hrs}$ in $\mathrm{Ni}$ ion concentration of $0.5 \mathrm{ppm}$, some morphological change, that is, linearization of cell was recognized. On the contrary, in case of cell after cultured $72 \mathrm{hrs}$ on $\mathrm{Ni}-\mathrm{Ti}$ alloy specimen surface with $\mathrm{TiO}_{2}$ thin film, no remarkable change in the morphology of cell was generated. From these observed results, $\mathrm{TiO}_{2}$ thin film formed by air oxidization also extremely contributes to improve bio compatibility of Ti-Ni alloy.

3. Corrosion resistance of surface modified Ni-Ti alloy may be extremely improved when air oxidization was conducted under the condition of suppressed partial pressure oxygen and the sequential combination of electropolishing and air oxidation. In these cases, also remarkable improvement in biocompatibility of Ni-Ti alloy may be expected. 


\section{References}

[1] S. Miyazaki, Mechanical Properties of Shape Memory Alloys, Yokendo, Chap.1\& Chap.2, 1993.

[2] K. Tanaka, Transformation thermomechanics in shape memory alloys, JMS 48(2), pp.1341-49, 1999.

[3] F.J. Gil, and J.A. Planell, Shape memory alloys for medical applications, Journal of Engineering in Medicine, 212(6), pp.473-88, 1998.

[4] L. Torrisi, The Ni-Ti superelastic alloy application to the dentistry field, Bio-Medical Materials \& Engineering, 9(1), pp.39-47, 1998.

[5] T. Eliades, G. Eliades, AE. Athanasiou, and TG. Bradley, Surface characterization of retrieved $\mathrm{Ni}-\mathrm{Ti}$ orthodontic archwires, European Journal of Orthopedics, 22(3), pp. 317-26, 2000.

[6] J. Ryhanen, M. Kallioinen, W. Serlo, P.Peramaki, J.Junila, P. Sandvik, E. Niemala, J. Tuukkanen, Bone healing and mineralizaiton, implant corrosion, and trace metals after nickel-titanium shape memory metal intramedullary fixation, Journal of Biomedical Materials Research, 47(1), pp. 472-480, 1999.

[7] J.C. Wataha, P.E. Lookwood, M. Marek, M. Ghazi, Ability of Ni-contaitng biomaterial alloys to activate monocytes and endothelial cells in vitro, Journal of Biomedical Materials Research, 45(3), pp.251-57, 1999.

[8] J. Komotori et al., Effect of thermal oxidation treatment on surface characteristic and corrosion resistance of Ni-Ti shape memory alloy, Journal of the Society of Materials Science, Japan, 55(10), pp.965-970, 2006.

[9] Zhiqiang Niu, Xiaoyu Jia, Weiping, Wenyuan Chen, Reactive sputtering $\mathrm{TiO}_{2}$ films for surface coating of poly dimethylsiloxane, Applied Surface Science, A252, pp.2259-2264, 2006.

[10] M. Morita, T. Hashimoto, K. Yamauchi, Y. Suto, T. Homma and Y. Kimura, Evaluation of biocompatibility for Titanium-Nickel shape memory alloy in vivo and in vitro environment, Materials Transactions, 48(3), pp.352-360, 2007.

[11] T. Homma, Y. Kimura and M. Morita, Evaluation of compatibility of Nickel-Titanium shape memory alloy with femur surrounding tissue, Transactions of Materials Research Society of Japan, 28(3), pp.853-856, 2003.

[12] S. M. Green, D. M. Grant, J. V. Wood, XPS characterization of surface modified Ni-Ti shape memory alloy, Materials Science and Engineering, A224, pp.21-26, 1997. 